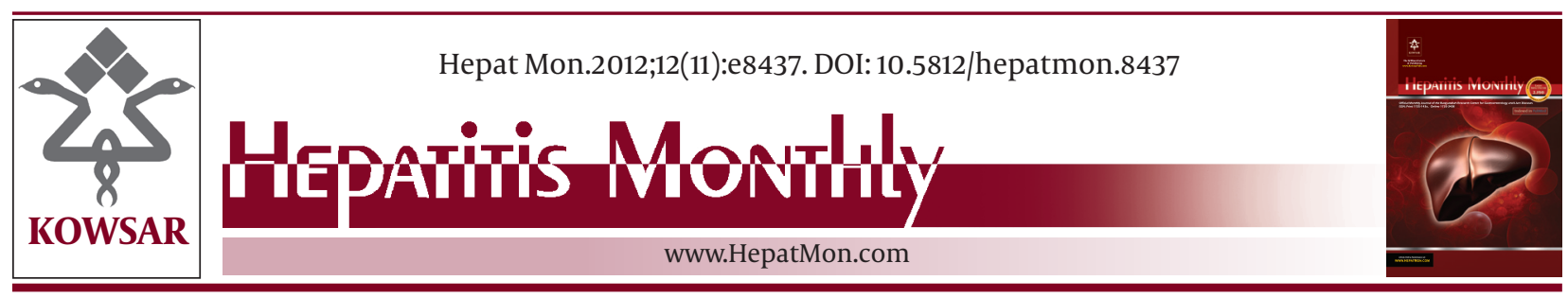

\title{
Xenon: A Solution for Anesthesia in Liver Disease?
}

\author{
Ali Dabbagh ${ }^{1^{*}}$, Samira Rajaei ${ }^{2}$ \\ ${ }^{1}$ Anesthesiology Research Center, Shahid Beheshti University of Medical Sciences, Tehran, IR Iran \\ ${ }^{2}$ School of Allied Medicine, Tehran University of Medical Sciences, Tehran, IR Iran
}

\section{A R T I C L E I N F O}

Article type:

Editorial

Article history:

Received: 15 Sep 2012

Revised: 01 Oct 2012

Accepted: 15 Oct 2012

\section{Keywords:}

Xenon

Liver

Anesthesia the first anesthesiologist using modern methods of anesthesia and describing them in his Canon textbook (1); however, the majority of clinicians of worldwide believe that the modern practice of anesthesia is not too much old since 1846 and has affected the fate of surgical era after its invention in $1846(2,3)$. From the first days, anesthesia has been based on a limited number of pharmaceuticals and among them, anesthetic gases have a major role (4). The anesthetic gases have reached a great development; reaching the latest versions of halogenated hydrocarbons; sevoflurane being the last and possibly one of the best members of this family after decades (3-5). However, each pharmaceutical might have some potential side effects and the volatile anesthetics are not exception for this fact; one of their main drawbacks is the possibility of volatile agent that induced hepatic injury (2-6). Though its incidence has declined dramatically after introduction of newer halogenated hydrocarbons like
- Implication for health policy/practice/research/medical education:

Anesthetics, especially the volatile anesthetics are a major concern in all the patients undergoing surgical operations. None of the recent agents have been considered the ideal gas for the liver; however, Xenon, a member of the Noble gas family, has a considerable number of ideal characteristics which are discussed here.

- Please cite this paper as:

Dabbagh A, Rajaei S. Xenon: A Solution for Anesthesia in Liver Disease? Hepat Mon. 2012; 12(11):e8437. DOI: 10.5812/hepatmon.8437

Published by Kowsar Corp, 2012. cc 3.0.

sevoflurane and desflurane, it has not vanished totally and studies regarding different effects of these gases are among the current research priorities (7-9). So, there is a widespread search for finding safer anesthetic gases with fewer side effects. Xenon, a member of the noble gas family, was discovered for the first time in 1898 (10). However, its anesthetic properties were first described at 1939 (10) and it received more intense attention at 1951 when anesthetic properties of xenon and krypton were reported in Science Journal $(11,12)$. But its clinical use was not so much a matter of interest; then, it took about 40 years to rediscover it for any possible clinical application $(13,14)$. The mechanism of xenon anesthesia is its effect on the Nmethyl-D-aspartate receptors through noncompetitive inhibition (10). At the present time, there is a growing enthusiasm between clinicians to use it as an anesthetic; since it has "nearly all" the characteristics of an ideal anesthetic gas (15-20). However, it has two main drawbacks: very high price $(13,21,22)$ and the problems related to

${ }^{*}$ Corresponding author: Ali Dabbagh, Anesthesiology Research Center, Shahid Beheshti University of Medical Sciences, Tehran, IR Iran. Tel: +98-2122074090, Fax: +98-212243 2572, E-mail: alidabbagh@yahoo.com

DOI: $10.5812 /$ hepatmon.8437

Copyright@ 2012 Kowsar Corp. All rights reserved.

This is an Open Access article distributed under the terms of the Creative Commons Attribution License (http://creativecommons.org/licenses/by/3.0), which permits unrestricted use, distribution, and reproduction in any medium, provided the original work is properly cited. 
drug scavenging $(2,10,23)$. Technology has improved and the more newer technologies used in updated anesthesia machines has helped us to decrease the waste of gas; so gas wastage has decreased both needed dose and the scavenging needs $(2,10,13,21)$. In most circumstances, xenon is an inert gas, producing effective inhalational anesthesia under norm baric condition (24-30); having "nearly all" the necessary features of an ideal anesthetic gas (16-20) producing a very steady state regarding the left ventricular function, with ulmost cardiovascular stability and fewer "fluctuations of cardiovascular system parameters"; only some right ventricular function impairment has been noted $(14,18,31,32)$. Also, xenon does not have "negative inotropic effects and vasodilatation" which is a very important and useful characteristic for patients with depressed cardiovascular function and are not hemodynamically stable; with very low incidence of toxicity or teratogenicity (22). At the same time, in clinical conditions, has been shown to exert protection of brain or myocardium from ischemia-reperfusion injury (14, $33,34)$. These protective effects are of course, among all the members of the inert gas family, it is the only clinical agent having anesthetic actions (14). But the organ protective effect of noble gas family members is not limited to xenon; it should be said that xenon is the only member of the family having organ protection effects and clinical anesthetic effects $(14,24)$. For example, helium has organ protecting effects without anesthetic effects (24). There are many studies regarding the effects of xenon as an anesthetic on the liver; directly or indirectly; some being animal and others clinical studies (2, 10, 21, 22, 31, 34-39). Xenon anesthesia helps us prevent liver exposure to halogenated anesthetic gases; so the liver cells are not exposed to these agents; while xenon has not demonstrated any possible liver cell injury but it possibly would protects these cells (2); especially when considering the organ-protective effects of xenon (37). Also, xenon anesthesia has much better results regarding the tumor size after laparoscopy in rats compared with $\mathrm{CO} 2$, decreasing the size of tumor after using helium or xenon pneumoperitoneum possibly by their inflammatory modification effects (35). Xenon anesthesia has been shown to produces "the highest regional blood flow in the brain, liver, kidney and intestine" (22); which is a very interesting effect for patients undergoing liver surgeries like liver transplant $(22,23)$ which could induce a "feasible" anesthesia for liver transplant with satisfactory situation in the "immediate postoperative liver function" (34). Also, xenon causes the flow of the hepatic artery to remain stable with no vivid "change in the hepatic arterial buffer responses" (31). Also, it was demonstrated that xenon anesthesia could reduce "plasma catecholamine concentrations" which would result in improved nitrogen balance after surgery (38). The patients undergoing anesthesia with xenon for liver surgeries tolerate less fluctuations in "liver circulation parameters" so, the perfusion status of the liver is much better preserved with xenon anesthesia. We still need more studies to see whether we could decrease the costs of xenon anesthesia by developing newer anesthesia machines decreasing wastage of anesthetics to the environment; in such a way that its many benefits could overcome the costs. The primary studies have demonstrated that improved circulatory equipments could improve the clinical outcome when using xenon anesthesia (17). Helium when used instead of carbon dioxide for laparoscopy could decrease the size of tumor after surgery (35). Except for xenon, krypton and argon are also potential anesthetic gases (13). Even, krypton has been shown to have better results in animal studies; while not yet proved in clinical studies. Finally, at the present time, xenon is used limitedly in European and the US for some very critical patients like hepatic transplantation; however, using its beneficial effects instead of the routine volatile agents depends on the improvement of new recycling anesthesia machines with rebreathing system properties providing efficient cost containment approaches $(13,35)$.

\section{Authors' Contribution}

AD took part in study design and implementation, preparation of the text, submission and final review. SR took part in study design and implementation and preparation of the text.

\section{Financial Disclosure}

None declared.

\section{References}

1. Ben Rejeb A, Mamissi N. [Anesthesia and resuscitation in AraboIslamic medicine: analytic study through Ibn Sina]. Tunis Med. 2000;78(2):146-51.

2. Bovill JG. Inhalation anaesthesia: from diethyl ether to xenon Handb Exp Pharmacol. 2008(182):121-42.

3. Habibollahi P, Mahboobi N, Esmaeili S, Safari S, Dabbagh A, Alavian SM. Halothane-induced hepatitis: A forgotten issue in developing countries: Halothane-induced hepatitis. Hepat Mon 2011;11(1):3-6.

4. Mahboobi N, Esmaeili S, Safari S, Habibollahi P, Dabbagh A, Alavian SM. Halothane: how should it be used in a developing country? East Mediterr Health J. 2012;18(2):159-64.

5. Dabbagh A, Rajaei S. Halothane: Is there still any place for using the gas as an anesthetic? Hepat Mon. 2011;11(7):511-2.

6. Bedirli N, Ofluoglu E, Kerem M, Utebey G, Alper M, Yilmazer $D$, et al. Hepatic energy metabolism and the differential protective effects of sevoflurane and isoflurane anesthesia in a rat hepatic ischemia-reperfusion injury model. Anesth Analg. 2008;106(3):830-7, table of contents.

7. Cheng L, You Q, Yin H, Holt M, Franklin C, Ju C. Effect of polyI:C cotreatment on halothane-induced liver injury in mice. Hepatology. 2009;49(1):215-26.

8. Osman ES, Khafagy HF, Samhan YM, Hassan MM, El-Shanawany FM, Fathallah AR, et al. In vivo effects of different anesthetic agents on apoptosis. Korean J Anesthesiol. 2012;63(1):18-24.

9. Schifilliti D, Grasso G, Conti A, Fodale V. Anaesthetic-related neuroprotection: intravenous or inhalational agents? CNS Drugs. 2010;24(11):893-907.

10. Jordan BD, Wright EL. Xenon as an anesthetic agent. AANA J. 
2010;78(5):387-92.

11. Cullen SC, Gross EG. The anesthetic properties of xenon in animals and human beings, with additional observations on krypton. Science. 1951;113(2942):580-2.

12. Pittinger CB, Featherstone RM, Cullen SC, Gross EG. Comparative in vitro study of guinea pig brain oxidations as influenced by xenon and nitrous oxide. J Lab Clin Med.1951;38(3):384-7.

13. Kennedy RR, Stokes JW, Downing P. Anaesthesia and the 'inert' gases with special reference to xenon. Anaesth Intensive Care. 1992;20(1):66-70.

14. Preckel B, Weber NC, Sanders RD, Maze M, Schlack W. Molecular mechanisms transducing the anesthetic, analgesic, and organprotective actions of xenon. Anesthesiology. 2006;105(1):187-97.

15. Bickler PE, Warren DE, Clark JP, Gabatto P, Gregersen M, Brosnan $H$. Anesthetic protection of neurons injured by hypothermia and rewarming: roles of intracellular $\mathrm{Ca} 2+$ and excitotoxicity. Anesthesiology. 2012;117(2):280-92.

16. Chakkarapani E, Thoresen M, Liu X, Walloe L, Dingley J. Xenon offers stable haemodynamics independent of induced hypothermia after hypoxia-ischaemia in newborn pigs. Intensive Care Med. 2012;38(2):316-23.

17. Faulkner SD, Downie NA, Mercer CJ, Kerr SA, Sanders RD, Robertson NJ. A xenon recirculating ventilator for the newborn piglet: developing clinical applications of xenon for neonates. Eur J Anaesthesiol. 2012;29(12):577-85.

18. Hocker J, Grunewald M, Bein B. [Xenon anaesthesia--clinical characteristics, benefits and disadvantages and fields of application]. Anasthesiol Intensivmed Notfallmed Schmerzther. 2012;47(6):37480.

19. Kulikov A, Rylova A, Lubnin A. Awake craniotomy under xenon anesthesia: first experience. J Neurosurg Anesthesiol. 2012;24(2):1656.

20. Neukirchen M, Hipp J, Schaefer MS, Brandenburger T, Bauer I, Winterhalter M, et al. Cardiovascular stability and unchanged muscle sympathetic activity during xenon anaesthesia: role of norepinephrine uptake inhibition. BrJ Anaesth. 2012.

21. Derwall M, Coburn M, Rex S, Hein M, Rossaint R, Fries M. Xenon recent developments and future perspectives. Minerva Anestesiol. 2009;75(1-2):37-45.

22. Hecker K, Baumert JH, Horn N, Rossaint R. Xenon, a modern anaesthesia gas. Minerva Anestesiol. 2004;70(5):255-60.

23. Leclerc J, Nieuviarts R, Tavernier B, Vallet B, Scherpereel P. [Xenon anesthesia: from myth to reality]. Ann Fr Anesth Reanim. 2001;20(1):70-6.

24. De Hert SG, Preckel B, Schlack WS. Update on inhalational anaesthetics. Curr Opin Anaesthesiol. 2009;22(4):491-5.

25. Noreika V, Jylhankangas L, Moro L, Valli K, Kaskinoro K, Aantaa R, et al. Consciousness lost and found: subjective experiences in an unresponsive state. Brain Cogn. 2011;77(3):327-34.

26. Schaper C, Hocker J, Bohm R, Roeder T, Bein B. The shaker potas- sium channel is no target for xenon anesthesia in short-sleeping Drosophila melanogaster mutants. ScientificWorldjournal. 2012;2012:373709.

27. Stoppe C, Cremer J, Rex S, Schalte G, Fahlenkamp AV, Rossaint $\mathrm{R}$, et al. Xenon anaesthesia for laparoscopic cholecystectomy in a patient with multiple chemical sensitivity. $\mathrm{Br} J$ Anaesth. 2011;107(4):645-7.

28. Uchida T, Suzuki S, Hirano Y, Ito D, Nagayama M, Gohara K. Xenon-induced inhibition of synchronized bursts in a rat cortical neuronal network. Neuroscience. 2012;214:149-58.

29. Vizcaychipi MP, Lloyd DG, Wan Y, Palazzo MG, Maze M, Ma D. Xenon pretreatment may prevent early memory decline after isoflurane anesthesia and surgery in mice. PLoS One. 2011;6(11):e26394

30. Yamamoto E, Akimoto T, Shimizu H, Hirano Y, Yasui M, Yasuoka K. Diffusive nature of xenon anesthetic changes properties of a lipid bilayer: molecular dynamics simulations. J Phys Chem B. 2012;116(30):8989-95.

31. Iber T, Hecker K, Vagts DA, Roesner JP, Otto B, Steinicke A, et al. Xenon anesthesia impairs hepatic oxygenation and perfusion in healthy pigs. Minerva Anestesiol. 2008;74(10):511-9.

32. Weber NC, Toma O, Wolter JI, Obal D, Mullenheim J, Preckel B, et al. The noble gas xenon induces pharmacological preconditioning in the rat heart in vivo via induction of PKC-epsilon and p38 MAPK. Br JPharmacol. 2005;144(1):123-32.

33. Preckel B, Weber N, Schlack W. [Xenon - noble gas with organprotective properties]. Anasthesiol Intensivmed Notfallmed Schmerzther. 2004;39(8):456-62.

34. Wilke HJ, Moench C, Lotz G, Bechstein W, Zacharowski K. Xenon anesthesia for liver transplant surgery: a report of four cases. Transplant Proc. 2011;43(7):2683-6.

35. Dahn S, Schwalbach P, Maksan S, Wohleke F, Benner A, Kuntz C. Influence of different gases used for laparoscopy (helium, carbon dioxide, room air, and xenon) on tumor volume, histomorphology, and leukocyte-tumor-endothelium interaction in intravital microscopy. Surg Endosc. 2005;19(1):65-70.

36. Dahn S, Schwalbach P, Wohleke F, Benner A, Kuntz C. Influence of different gases used for laparoscopy (helium, carbon dioxide, room air, xenon) on tumor volume, proliferation, and apoptosis. Surg Endosc. 2003;17(10):1653-7.

37. Dingley J, Tooley J, Porter H, Thoresen M. Xenon provides shortterm neuroprotection in neonatal rats when administered after hypoxia-ischemia. Stroke. 2006;37(2):501-6.

38. Reinelt H, Marx T, Kotzerke J, Topalidis P, Luederwald S, Armbruster $\mathrm{S}$, et al. Hepatic function during xenon anesthesia in pigs. Acta Anaesthesiol Scand. 2002;46(6):713-6.

39. Schmidt M, Marx T, Kotzerke J, Luderwald S, Armbruster S, Topalidis $\mathrm{P}$, et al. Cerebral and regional organ perfusion in pigs during xenon anaesthesia. Anaesthesia. 2001;56(12):1154-9. 